\title{
CLINICAL CORRELATION AND LABORATORY DIAGNOSIS OF BACTERIAL VAGINOSIS
}

\author{
Kirti Malpekar1, Kumar Vivek2 ${ }^{2}$ Jayanthi Shastri ${ }^{3}$
}

${ }^{1}$ Associate Professor, Department of Microbiology, Topiwala National Medical College, Nair Hospital, Mumbai.

${ }^{2}$ Senior Registrar, Department of Microbiology, Topiwala National Medical College, Nair Hospital, Mumbai.

3 Professor and HOD, Department of Microbiology, Topiwala National Medical College, Nair Hospital, Mumbai.

ABSTRACT
Bacterial vaginosis characterised by a heavy overgrowth of gram-negative and gram-positive anaerobes with no signs of
inflammation has been regarded as a microbiological and immunological enigma.

\section{AIMS AND OBJECTIVES}

1. To identify the causative organisms from clinically suspected cases of bacterial vaginosis. 2. To evaluate the accuracy of Amsel's clinical criteria and Nugent's Gram stain criteria for diagnosis of bacterial vaginosis. 3 . To correlate with other associated sexually transmitted infections.

\section{MATERIAL AND METHODS}

This prospective study involving total 600 non-pregnant women with abnormal vaginal discharge, clinically suspected cases of bacterial vaginosis (BV) attending the Gynaecology OPD at a tertiary care hospital was done over a period of one year. The following samples were collected from each subject: Three vaginal swabs and one blood sample ( $5 \mathrm{~mL})$. Three vaginal swabs were taken and immediately sent to the microbiology laboratory for processing, by microscopy and culture on appropriate media. For serological diagnosis of Hepatitis B and C, HIV, and VDRL testing, $5 \mathrm{~mL}$ blood was collected from cubital vein with aseptic precautions. The following parameters were noted - age, marital status, contraceptive use, presence of abnormal, recurrent, and/or foul-smelling vaginal discharge and clue cells. BV was diagnosed using Amsel's clinical criteria and Nugent's Gram stain criteria. Data was analysed using SPSS version 13, Fischer's exact test, and chi-square test.

\section{RESULTS}

BV occurred in 142/600 (23.7\%) women with abnormal vaginal discharge, 55/135 (40.7\%) were in age group 36-45 yrs., $140 / 593$ (23.6\%) married women and in 92/259 (35.5\%) women with recurrent vaginal discharge. Abnormal discharge was most commonly seen (193/600) women who had not used any contraceptives. Foul-smelling discharge was more in BV patients as compared to pain, itching, and burning micturition, which was more common in non-bacterial vaginosis (NBV) and had statistically significant $p$ value $(<0.05)$. Clue cells were seen in total 19/142 (13.3\%) patients suffering from BV. Based on Nugent's score, the 600 cases were classified as normal (223), intermediate (161), and BV (142). Based on aetiology, it was noted that mixed infection occurred in 42/600 cases: Vulvovaginal candidiasis (VVC) + intermediate in 24, BV+VVC in 16, and BV+Trichomoniasis in 2 . Majority of anaerobes, i.e. 100/136 (73.5\%) were found in BV patients. This association of anaerobes in BV was found to be significant with p-value $(<0.05)$. Yeast was grown in 105/600 (17.5\%); 16/105 (11.3\%) were significantly associated with BV $(p<0.05)$.

\section{CONCLUSION}

The Gram stain as interpreted by Nugent's criteria provides an objective, reproducible laboratory based test, and should be used in addition to clinical criteria for diagnosis of BV.

\section{KEYWORDS}

Bacterial Vaginosis (BV).

HOW TO CITE THIS ARTICLE: Malpekar K, Vivek K, Shastri J. Clinical correlation and laboratory diagnosis of bacterial vaginosis. J. Evolution Med. Dent. Sci. 2016;5(60):4148-4153, DOI: 10.14260/jemds/2016/948

\section{INTRODUCTION}

Bacterial vaginosis is characterised by a heavy overgrowth of gram-negative and gram-positive anaerobes with no signs of inflammation and regarded as a microbiological and immunological enigma. ${ }^{1}$ It occurs in up to $25 \%$ of the general population with more than half of the women being

Financial or Other, Competing Interest: None.

Submission 29-06-2016, Peer Review 12-07-2016,

Acceptance 19-07-2016, Published 26-07-2016.

Corresponding Author:

Dr. Kirti Malpekar,

\#404, Audumber So,

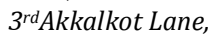

Khadilkar Road,

Girgaum, Mumbai-400004.

E-mail: kirtimalpekar@yahoo.co.in

DOI: $10.14260 /$ jemds $/ 2016 / 948$ asymptomatic. ${ }^{2}$. Although, its exact aetiology is unknown. It has been linked to high-risk sexual behaviours such as lack of condom use and multiple sex partners. ${ }^{3,4}$ The chief complaint is a malodorous vaginal discharge.2,5,6,7,8 It has a polymicrobial aetiology that includes Gardnerella vaginalis, Mycoplasma hominis, and various obligate anaerobes like Bacteroides, Prevotella, Porphyromonas, Peptostreptococcus, Peptococcus, Veillonella, Eubacterium, Mobiluncus,5,6,8,9 Peptoniphilus, and Fusobacterium.10 Many clinicians empirically diagnose the aetiology of a vaginal discharge without the aid of laboratory tests and this often leads to a misdiagnosis. 11,12 In view of this, the present study was done to identify the causative organisms from clinically suspected cases of BV among non-pregnant women compare the utility of various methods for the diagnosis of this condition and correlate the association with other associated sexually transmitted infections. 


\section{MATERIAL AND METHODS}

This prospective study involving total 600 non-pregnant women with abnormal vaginal discharge attending the Gynaecology OPD at a tertiary care hospital was done over a period of one year.

\section{Inclusion Criteria}

Young non-pregnant sexually active females with excessive vaginal discharge in the reproductive age group of 15-45 years.

\section{Exclusion Criteria}

Age below 15 years, age older than 45 years, pregnant, menstruating, history of antibiotics, and/or topical vaginal creams within seven days prior to the date of examination.

The Institutional Ethics Committee approval was taken. Informed consent of the participants was obtained. Participants were asked about their symptoms, past illness, and previous treatment before undergoing gynaecological examination. In the gynaecological OPD, after assuring the patient, a clean unlubricated Cusco's vaginal speculum was passed into the vagina to examine the condition of the vaginal wall, cervix, and characteristics of the discharge [with respect to amount, odour, and type of discharge, which was described as normal (Mucoid or floccular), purulent, curdy, or thin and homogenous. The following samples were collected from each subject: Three vaginal swabs and one blood sample $(5 \mathrm{~mL})$. The vaginal sample was collected by swabbing the posterior and lateral vaginal fornices with a cotton-tipped sterile swab. Three vaginal swabs were taken and immediately sent to the microbiology laboratory for processing. After aseptic precautions, $5 \mathrm{~mL}$ blood was collected from cubital vein, for serological diagnosis of Hepatitis $B$ and $C$ and the patient was directed to ICTC Centre for HIV and VDRL testing. In the laboratory, the processing was as follows: For the 3 vaginal swabs: 1 . First swab was immediately processed by inoculating on Brucella blood agar with Hemin and Vitamin $\mathrm{K}_{1}$ supplement for anaerobes, ${ }^{13}$ Human Blood Bilayer (HBT) agar for detection of Gardnerella vaginalis, New York City agar for Neisseria gonorrhoeae, and Sabouraud dextrose agar for Candida. 2. A second swab was used to inoculate a tube of thioglycollate broth by gently introducing the swab into the lower half of the tube and rubbing it against the wall of the tube. The swab was subsequently mixed with two drops of sterile saline on a clean glass slide and a coverslip was placed over it. This wet mount was immediately examined using bright field microscopy under high power objective $(\mathrm{x} 40)$ for clue cells and jerking motility of Trichomonas vaginalis. 3. Third swab was used for smear, $\mathrm{pH}$ test, whiff test, and $\mathrm{KOH}$ mount the swab was then mixed with 2 drops of $10 \%$ potassium hydroxide on a slide and immediately held close to nose to detect the fishy odour associated with volatile amines (Whiff amine test). A diagnosis of BV was made using Amsel's clinical criteria5, if three of the following four criteria were present: A thin, homogenous discharge with milk-like consistency tending to adhere to the vaginal vault, Vaginal $\mathrm{pH}>4.5$, positive whiff amine test, and presence of clue cells. For diagnosis by Nugent's Gram stain criteria: Morphotypes were scored as the average number seen per oil immersion field. A total of 100 fields were examined for each slide. Total score=Lactobacillus+Gardnerella and Bacteroides spp. + curved rods. ${ }^{14}$ Women who had a score of 7 or higher were considered to have BV, score of 4-6 were termed as intermediate vaginal flora and $0-3$ as normal flora. For detection of yeast, Gram stain was screened for the presence of gram-positive budding yeast cells, and pseudohyphae. The presence of intracellular gram-negative diplococci within the polymorphonuclear leucocytes was presumptively diagnosed as Neisseria gonorrhoeae. For culture identification of anaerobes, Brucella blood agar with Hemin and Vitamin $\mathrm{K}_{1}$ supplement was incubated for 48 hours and examined for growth. The plates were kept for 7 days before final examination and then discarded. The thioglycollate broth was kept for 7 days at $37^{\circ} \mathrm{C}$. If no anaerobes were isolated from the primary plates after 7 days incubation, then the broth was subcultured onto Brucella blood agar with Hemin and Vitamin K1 supplement plates. For identification of anaerobes: Each distinct anaerobe colony was examined and its morphology noted. A portion of the colony was Gram stained and inoculated onto the following media: 1) Chocolate agar plate incubated in a candle jar for 48 hours to test the isolate for aerotolerance. 2) Brucella blood agar with Hemin and Vitamin $\mathrm{K}_{1}$ supplement for the antibiotic identification test. $1 \mathrm{mg}$ kanamycin disc, $5 \mu \mathrm{g}$ vancomycin disc, and $10 \mu \mathrm{g}$ Colistin disc were placed well separated from each other. The plate was incubated anaerobically for 48 hours at $37^{\circ} \mathrm{C}$. A zone diameter of $\leq 10 \mathrm{~mm}$ indicated resistance while a zone diameter $>10 \mathrm{~mm}$ indicated sensitivity. For Gardnerella vaginalis: Human Blood Bilayer with Tween (HBT) agar with selective supplement (From HiMedia) and New York City (NYC) agar with NYC supplement (From HiMedia) were inoculated. Sodium polyanethole sulfonate (SPS) disc indicator was used. Both HBT and NYC agar plates were incubated at $37^{\circ} \mathrm{C}$ for $48 \mathrm{hrs}$. and $72 \mathrm{hrs}$. respectively in a $\mathrm{CO}_{2}$ enriched humid atmosphere achieved by using candle jar. The blood sample was kept in room temperature for a minimum $1 \mathrm{hr}$ and the serum was used for the following tests: ELISA for anti-HCV detection (3 $3^{\text {rd }}$ generation) (SD Bioline) and ELISA for HBsAg detection (Sun Pharma).

\section{RESULTS}

In this prospective study involving a total of 600 non-pregnant women with abnormal vaginal discharge, 142/600 (23.7\%) had BV. The distribution of cases based on Nugent's score was as follows: normal group: 223 followed by intermediate: 161 and BV: 142 (Table 1). Based on aetiology, it was seen that mixed infection occurred in 42/600 cases: Vulvovaginal candidiasis (VVC)+Intermediate in 24, BV+VVC in 16 and BV+ Trichomoniasis in 2 (Table 2). BV was commonly seen in 36-45 yrs. age group: 55/135(40.7\%), which was statistically significant $\mathrm{p}$ value $(<0.05)$. Married women comprised 593/600(98.8\%); BV occurred in 140/593(23.6\%) of them. Recurrent vaginal discharge occurred in $259 / 600$ of which 92(35.5\%) were associated with BV. This association was significant with Pearson chi-square $(\chi 2) 35.405$, continuity correction 34.305, df-1 and p-value of 4.71E-09. Abnormal discharge was most commonly seen (193/600) in women who had not used any contraceptives. Majority of the women with BV were sterilised with TL (55/142); very few used OC pills (1/142), condom (10/142), and other methods (10/142) such as diaphragm, sponge, spermicidal jelly/foam, etc. Foul smelling discharge was more in BV patients as compared to pain, itching, and burning micturition, which was more common in NBV, and was statistically significant $p$ value $(<0.05)$. Clue cells were seen in a total of $19 / 142(13.3 \%) \mathrm{BV}$ patients of which majority i.e. 13/19 had Nugent's score of 8 
followed by 4/19 with Nugent's score of 7 and one each with Nugent's score of 9 and 10 . Amsel's criteria were able to detect BV in 167/600 (27.8\%) [Table 3]. Of these, Nugent's Gram stain criteria was negative in 50 . On the contrary, 25 patients who did not satisfy the Amsel's clinical criteria were positive by Nugent's Gram stain. The inter-rater agreement statistic (Kappa) was determined between the Amsel's criteria and Nugent's score (Kappa $=0.674)$. Majority of anaerobes i.e. $100 / 136$ (73.5\%) were found in BV patients. This association of anaerobes in $\mathrm{BV}$ was found to be significant with p-value $(<0.05)$. Curved gram-negative rods suggestive of Mobiluncus spp. were most commonly seen microscopically in BV cases (30.3\%) followed by Peptostreptococcus spp. (27.5\%) and Bacteroides spp. (21.8\%). Gardnerella vaginalis was not isolated. Yeast was grown in 105/600 (17.5\%), 16/105 $(11.3 \%)$ were significantly associated with BV $(\mathrm{p}<0.05)$. In our study, HIV infection was seen in $0.7 \%$, HBV infection occurred in $0.3 \%$, and HCV occurred in $0.2 \%$.

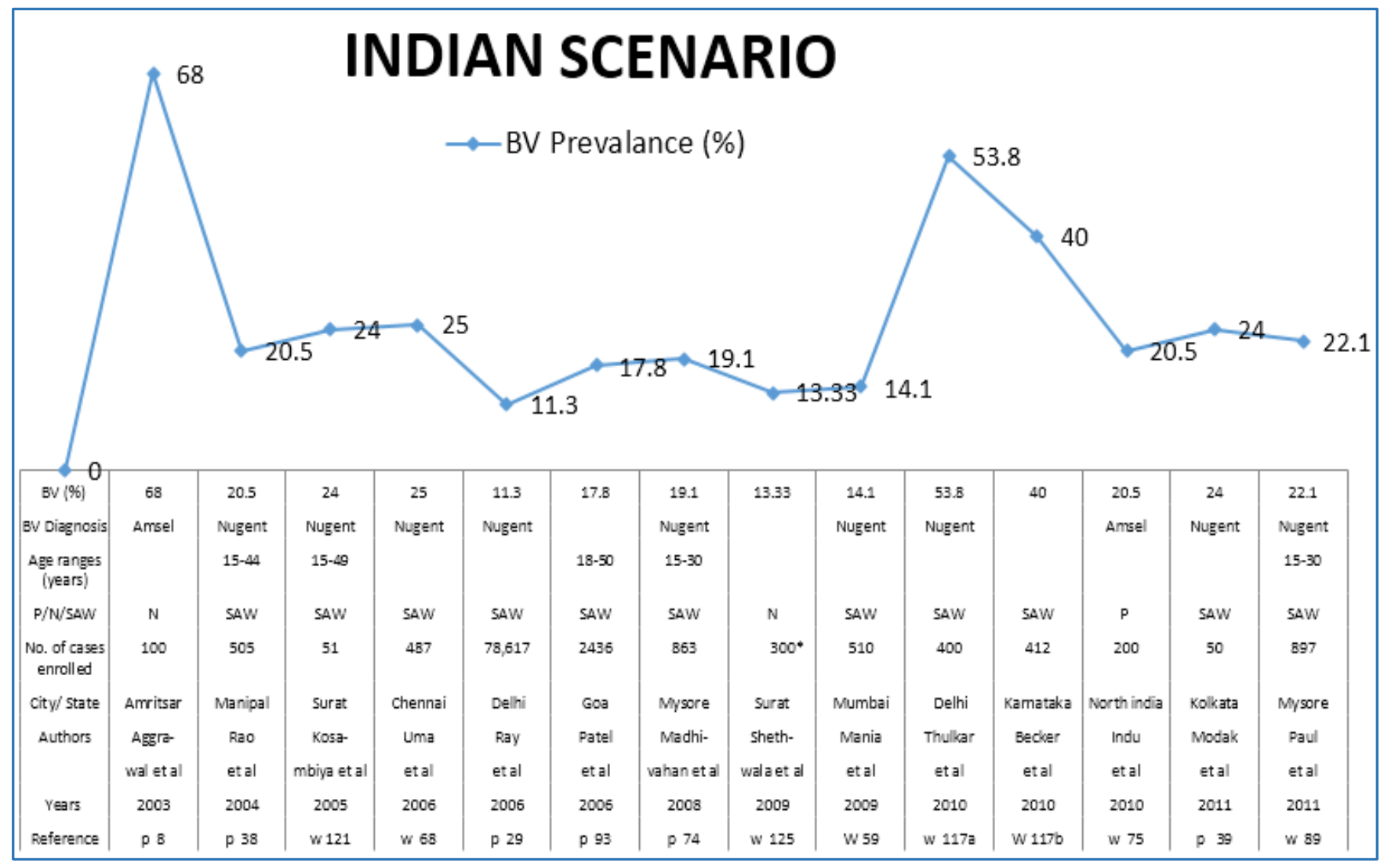

Fig. 1: Bacterial Vaginosis in Different Cities/States in India

(In the present study, BV was diagnosed in $23.7 \%$ based on Nugent's criteria).

${ }^{*} \mathrm{~N}=$ Non-pregnant; $\mathrm{P}=$ Pregnant; $\mathrm{SAW}=$ Sexually active women.

\begin{tabular}{|c|c|c|}
\hline Diagnosis (3 Groups) & No. & Percentage \\
\hline BV & 142 & $23.7 \%$ \\
\hline Intermediate & 161 & $26.8 \%$ \\
\hline Normal & 297 & $49.5 \%$ \\
\hline Total & 600 & $100.0 \%$ \\
\hline Table 1: Distribution Based on Nugent's Score Criteria* \\
\hline
\end{tabular}

*Nugent's score: BV 7-10; Intermediate-4-6; Normal 0-3.

For diagnosis by Nugent's Gram stain criteria14: Morphotypes were scored as the average number seen per oil immersion field. A total of 100 fields were examined for each slide. Total score $=$ Lactobacillus + Gardnerella and Bacteroides spp.+curved rods. Women who had a score of 7 or higher were considered to have BV, score of 4 - 6 were termed as intermediate vaginal flora, and $0-3$ as normal flora.

\begin{tabular}{|c|c|c|}
\hline Diagnosis & No. & Percentage \\
\hline Intermediate* $^{*}$ & 137 & $22.8 \%$ \\
\hline BV (Bacterial Vaginosis )* $^{*}$ & 124 & $20.7 \%$ \\
\hline VVC (Vulvovaginal candidiasis) $^{*}$ & 65 & $10.8 \%$ \\
\hline VVC+Intermediate & 24 & $4.0 \%$ \\
\hline BV+VVC & 16 & $2.7 \%$ \\
\hline Trichomoniasis & 7 & $1.2 \%$ \\
\hline BV+Trichomoniasis & 2 & $0.3 \%$ \\
\hline Gonorrhea & 2 & $0.3 \%$ \\
\hline Normal & 223 & $37.2 \%$ \\
\hline Total & 600 & $100.0 \%$ \\
\hline $\begin{array}{c}\text { Table 2: Distribution of Cases of RTIs } \\
\text { (Reproductive Tract Infections) }\end{array}$ \\
\hline
\end{tabular}




\begin{tabular}{|c|c|c|c|c|c|c|c|c|c|}
\hline \multicolumn{2}{|c|}{ Clinical Sign } & BV & NBV & Total & Chi-Square Tests & Value & Df & p-Value & Association is- \\
\hline \multirow{2}{*}{$\begin{array}{c}\text { Thin Grey } \\
\text { Homogenous } \\
\text { Discharge }\end{array}$} & No. & 101 & 119 & 220 & Pearson Chi-Square & 95.127 & 1 & $1.79 \mathrm{E}-22$ & Significant \\
\hline & $\%$ & $71.1 \%$ & $26.0 \%$ & $36.7 \%$ & Continuity Correction & 93.193 & 1 & $4.74 \mathrm{E}-22$ & Significant \\
\hline & No. & 126 & 121 & 247 & Pearson Chi-Square & 173.777 & 1 & $1.11 \mathrm{E}-39$ & Significant \\
\hline & $\%$ & $88.7 \%$ & $26.4 \%$ & $41.2 \%$ & Continuity Correction & 171.214 & 1 & $4.02 \mathrm{E}-39$ & Significant \\
\hline \multirow{2}{*}{ Whiff Test } & No. & 124 & 71 & 195 & Pearson Chi-Square & 254.875 & 1 & $2.25 \mathrm{E}-57$ & Significant \\
\hline & $\%$ & $87.3 \%$ & $15.5 \%$ & $32.5 \%$ & Continuity Correction & 251.612 & 1 & $1.16 \mathrm{E}-56$ & Significant \\
\hline \multirow{2}{*}{ Clue Cells } & No. & 19 & 0 & 19 & Pearson Chi-Square & 63.286 & 1 & $1.79 \mathrm{E}-15$ & Significant \\
\hline & $\%$ & $13.4 \%$ & $0.0 \%$ & $3.2 \%$ & Continuity Correction & 58.997 & 1 & $1.58 \mathrm{E}-14$ & Significant \\
\hline
\end{tabular}

\section{DISCUSSION}

In our study involving 600 non-pregnant women with abnormal vaginal discharge, BV was diagnosed in $23.7 \%$ (Based on Nugent's criteria). Among the Indian studies, Adamson et al ${ }^{15}$ Modak et al ${ }^{16}$ Uma et $\mathrm{al}^{17}$ and Kosambiya et al ${ }^{18}$ reported similar results (Fig. 1). Higher rate have been reported by Becker et al ${ }^{19}$ Thulkar et al ${ }^{20}$ and Aggrawal et al ${ }^{21}$ Slightly lower rate was reported by Indu et al ${ }^{22}$ Madhivanan et $\mathrm{al}^{4}$ Patel et $\mathrm{al}^{23}$ whereas very low infection was noted by Mania et al ${ }^{24}$ Shethwala et al ${ }^{25}$ and Ray et al ${ }^{26}$ Highest number (68\%) was noted in a study by Aggrawal et al ${ }^{21}$ where Amsel's clinical criteria was used as standard. Also, a meta-analysis by Gillet et $\mathrm{al}^{27}$ showed a higher rate (32\%). In our study, Vulvovaginal Candidiasis (VVC) was noted in 14.8\%; similar findings were reported $14 \%$ by Kosambiya et al ${ }^{18}$ in Surat, India and $15.7 \%$ River et al ${ }^{28}$ in USA. Higher rate of VVC, $17.4 \%$ was noted by Esim et al ${ }^{29}$ and Xiao et $\mathrm{al}^{30}(21.87 \%)$ in China. Indu et al ${ }^{22}$ reported $9 \%$, which was low. In our study, $2.27 \%$ cases had mixed infection of BV/VVC, which was close to $4.4 \%$ reported by River et $\mathrm{al}^{28} 3 \%$ by Indu et $\mathrm{al}^{22}$ in North India and $4.2 \%$ by Mania et $\mathrm{al}^{24}$ in Mumbai; slightly less (1.36\%) was found by Xiao et al. $^{30}$ In our study, Trichomoniasis was seen in $9 / 600$ (1.5\%) and mixed infection of BV/Trichomoniasis in 2/600 (0.3\%). Similar reports from India are: $1.4 \%$ by Sunita et al ${ }^{31}$ $1.2 \%$ by Patel et al $231.18 \%$ by Rao et al $321.2 \%$ by Ray et al. 26 Reports by Shethvala et al 25 (2\%), Bhalla et al 33 2.8\%, Thulkar et al20 6.74\%, Adamson et al 8.5\%,15 Bogearts et al 2\%,34 and Kosambiya et al $22 \%{ }^{18}$ showed higher number of cases. Studies from China reported lower infection $1.7 \%$ Youngin et al ${ }^{35}$ and $0.67 \%$ Liu et al. ${ }^{36}$ In the present study, majority of women with abnormal discharge 240/600 (40\%) belonged to the 26-35 yrs. age group among them BV occurred in 66/240 (27.5\%). Older age group (36-45 yrs.) comprised 135/600 (22.5\%) and BV occurred in 55/135 (40.7\%) of them. Sumati et al ${ }^{37}$ noted that $60.11 \%$ patients were between 26 to 40 years of age and BV occurred in $52 \%$ in this age group. The mean SD (Standard deviation) and median age (Yrs.) of all cases are 29.59, 6.97, and 29 respectively whereas in BV it was $32.46,6.10$, and 33 respectively. This difference was significant with p-value 1.59 E-09 $(<0.05)$. Modak et $\mathrm{l}^{16}$ found the mean SD and median of overall cases to be $30.7,10.46$, and 30 almost similar to us; however, in BV cases these were 28.33, 7.90, and 29.5 respectively, which is less compared to us. In our study, married women were 593/600 (98.8\%) and 7 were widowed, which is similar to Madhivanan et $\mathrm{al}^{4}$ and Modak et al ${ }^{16}$ Abnormal discharge was higher among women who had not used any contraceptives (193/600). Maximum women associated with $\mathrm{BV}$ had undergone sterilization with TL (55/142). Patel et al ${ }^{23}$ reported similar findings. We noted that abdominal pain, itching, and burning micturition, all three inflammatory signs were less in BV compared to NBV, which was significant. In present study, $36.62 \%$ of BV patients had abdominal pain whereas it was higher $(58.52 \%)$ in NBV patients. Bhalla et $\mathrm{al}^{33}$ reported abdominal pain in $24.3 \% \mathrm{BV}$ patient and Patel et al ${ }^{23}$ in only $18.6 \%$. Itching was noted in $247 / 600(41.2 \%)$ of total patients and 17/142 (11.97\%) of BV cases. Kosambiya et al 18 reported itching in 10/42 (23.8\%) patients with discharge and Patel et al ${ }^{23}$ in $19.3 \%$ of BV cases. In present study, burning micturition was seen in $241 / 600$ and $30 / 241$ (12.4\%) had BV, which was lower than $20.4 \%$ by Patel et $\mathrm{al}^{23}$ In our study, $88.03 \% \mathrm{BV}$ cases had foul-smelling discharge compared to $18.12 \%$ in NBV, which was similar to $68.6 \%$ and $100 \%$ by Figueiredo et $\mathrm{al}^{38}$ and Hapsari et al ${ }^{39}$ in BV. The present study showed that grey thin homogenous discharge was more common in BV patients (71.12\%) similar to $84 \%$ seen by Aggrawal et al $^{21}$ Grey thin homogenous discharge had sensitivity, specificity, positive, and negative predictive values of $71.13 \%, 74.02 \%, 45.91 \%$, and $89.21 \%$ respectively similar to Modak et al ${ }^{16}$ (66.67\%, 71.05\%, 42\%, and $87 \%$ respectively). Whiff test in present study had sensitivity, specificity, positive and negative predictive value of $87.32 \%, 84.50 \%, 63.59 \%$, and $95.56 \%$ (Table 3). Modak et al ${ }^{16}$ findings have shown sensitivity, specificity, positive, and negative predictive value of $41.67 \%, 100 \%, 100 \%$, and $84 \%$ respectively; sensitivity being lower. Aggrawal et al ${ }^{21}$ reported sensitivity of $68 \%$ while Hainer et al 40 observed a sensitivity and specificity of $77 \%$ and $93 \%$ respectively. Clue cells found in our study was $19 / 600$ (3.2\%) similar to $1.07 \%$ by Sunita et al. ${ }^{31}$ The presence of clue cells was the most specific of all the criteria (Specificity $=100 \%$ ). It also had the highest predictive value of a positive test (100\%). But, presence of clue cells was not found to be very sensitive (Sensitivity $=13.38 \%$ ) and gave a large number of false negative cases $(86.6 \%)$ with negative predictive value of $78.82 \%$. In our study, $\mathrm{pH}>4.5$ had sensitivity, specificity, positive, and negative predictive values of $88.73 \%, 73.58 \%, 51.01 \%$, and $95.47 \%$ respectively. Modak et al 16 noted similar findings: $83.33 \%, 86.84 \%, 67 \%$, and $94 \%$ respectively. $88 \%$ of sensitivity was also observed by Aggrawal et al ${ }^{21}$ Ultimately, $\mathrm{pH}$ seemed to be the best indicator of bacterial vaginosis, if all sensitivity, specificity, positive, and negative predictive values are taken into consideration. It was found to be most sensitive and had the best predictive value of a negative test. Furthermore, it is the one, which could be objectively measured at the bedside. In this study, the Amsel's criteria had a sensitivity of $82.39 \%$, specificity of $89.08 \%$, positive and negative predictive values of $70.06 \%$ and $94.23 \%$ respectively when compared to the Nugent's criteria. Modak et $\mathrm{al}^{16}$ also found sensitivity, specificity, positive, and negative predictive values $66.67 \%, 94.47 \%, 80 \%$, and $90 \%$ respectively. Similar parameters were reported by Schwebke et al ${ }^{41}$ with 
$70.40 \%, 94.40 \%, 89 \%$, and $83.10 \%$ respectively. Gallo et al ${ }^{42}$ found the sensitivity and specificity of Amsel's criteria as 60\% and $90 \%$ respectively; sensitivity being less compared to present study. Schwebke et $\mathrm{al}^{41}$ compared Amsel's clinical criteria with Nugent's criteria and showed that the Nugent criteria had a higher sensitivity of $89 \%$ and Amsel's criteria had a higher specificity of $94 \%$. It is suggested by many reports to consider Nugent's score as standard criteria as the comparatively low sensitivity of Amsel's criteria results in the decrease of true positive cases causing ineffective treatment. $16,24,20,15,43,44$ Pus cells were seen in $32 / 142(22.5 \%)$ of BV patients compared to $104 / 161(64.6 \%)$ of intermediate and 108/297(50.2\%) of normal group suggestive of noninflammatory characteristic of $\mathrm{BV}$. Sachdeva et $\mathrm{al}^{45}$ also observed that "vaginal discharge of patients with BV is notable for its lack of (Polymorphs) PMNs, typically 1 or less than 1 PMN per vaginal epithelial cell." Distribution of anaerobes was as follows: curved gram-negative rods suggestive of Mobiluncus spp. were most commonly seen microscopically in BV cases (30.3\%) followed by Peptostreptococcus spp. (27.5\%) and Bacteroides spp. (21.8\%). Evidence of association of anaerobic bacteria with BV is mounting. Aggrawal et al ${ }^{21}$ reported Peptostreptococcus spp. (53.30\%) as most common followed by Bacteroides spp. (16.7\%). Rao et $\mathrm{al}^{32}$ found Peptostreptococcus spp. and Prevotella spp. to be common among the anaerobes isolated. Sumati et al ${ }^{37}$ found Bacteroides spp. to be more common followed by Peptococcus spp. Curved gram-negative rods were also noted by Rao et al in $8.45 \%$ BV cases. In present study, Gardnerella vaginalis was not isolated. This may be due to inadvertent error in transport or inhibition by high concentration of $\mathrm{NACl}$ in the Columbia base agar used in the culture medium (Catnil et al) ${ }^{9}$ Various studies have reported isolation of Gardnerella vaginalis ranging from $10.2 \%$ Esin et al 29 7.32\% Rao et al ${ }^{32} 28 \%$ Khan et al ${ }^{46}$ to as high as 96.8\% Figueiredo et al38 Among the STIs in our study, gonorrhea occurred in $0.3 \%$, which was less compared to $0.5 \%$ of Bogaerts et al ${ }^{34} 1.9 \%$ of Patel et $\mathrm{al}^{23} 1 \%$ of Bhalla et al ${ }^{33} 1.7 \%$ of Youngin et al ${ }^{35} 15.8 \%$ of Wang et $\mathrm{al}^{47}$ and $16.11 \%$ of Liu et al. ${ }^{36}$ In our study, HIV infection was seen in $0.7 \%$, which was less than $0.87 \%$ of Sunita et al ${ }^{31} 11.6 \%$ of Shethwala et al ${ }^{25}$ and $0.95 \%$ of Bhalla et al. 33 In the present study, HBV infection occurred in $0.3 \%$, which was low compared to $3.33 \%$ by Shethwala et al 25 (India), $0.9 \%$ by Wang et al 47 (China), $0.67 \%$ by Liu et al114 (China) and highest 35\% reported by Bogaerts et al. ${ }^{34}$ In our study, HCV occurred in $0.2 \%$, which was low compared to $0.5 \%$ by Wang et al ${ }^{47}$ (China), $0.67 \%$ by Liu et al ${ }^{36}$ (China), and $0.9 \%$ reported by Bogaerts et $\mathrm{al}^{34}$ The limitation of the study was that we could not include Herpes and Chlamydia due to lack of funds. Further studies are required especially for detection of HBV and HCV infection in BV.

\section{CONCLUSION}

India has a high burden of reproductive morbidity and bacterial vaginosis has been documented as a risk factor for both adverse birth outcomes and HIV. Proper diagnosis of BV is challenging. It is often misdiagnosed using clinical criteria alone because the components are subjective. Many studies have suggested that the Gram stain be considered the gold standard for diagnosis of BV. Recently, although, newer diagnostic molecular methods have been devised, Nugent's and Amsel methods remain the most practical, viable, and economic option especially in developing countries.

\section{ACKNOWLEDGEMENT}

We acknowledge the cooperation of the faculty and staff of Obstetrics and Gynaecology and Microbiology Department, TN Medical College and BYL Nair Hospital, Mumbai.

\section{REFERENCES}

1. Danielsson D, Teigen PK, Moi H. The genital econiche: focus on microbiota and bacterial vaginosis. Ann N Y Acad Sci 2011;1230:48-58.

2. Amsel R, Totten PA, Spiegel CA, et al. Nonspecific vaginitis: diagnostic criteria and microbial and epidemiologic associations. Am J Med 1983;74(1):14-22.

3. Brotman RM, Klebanof MA, Nansel TR, et al. A longitudinal study of vaginal douching and bacterial vaginosis-a marginal structural modeling analysis. Am J epidemiol 2008;168(2):188-96.

4. Madhivanan P, Krupp K, Chandrasekaran V, et al. Prevalence and correlates of bacterial vaginosis among young women of reproductive age in Mysore, India. Indian Journal of Medical microbiology 2008;26(2): 132-7.

5. Spiegel CA. Bacterial vaginosis. Clin Micobiol Rev 1991;4(4):485-502.

6. Pheifer TA, Forsyth PS, Durfee MS, et al. Nonspecific vaginitis: role of Haemophilus vaginalis and treatment with metronidazole. N Eng J Med 1978;298(26):1429-34.

7. Chen KC, Forsyth PS, Bucchanan TM, et al. Amine content of vaginal fluid from untreated patients with nonspecific vaginitis. J Clin Invest 1979;63(5):828-35.

8. Blackwell A, Barlot D. Clin diagnosis of anaerobic vaginosis (nonspecific vaginitis). BR J Vener Dis 1982;58(6):387-93.

9. Catlin VW. Gardnerella vaginalis: characteristics, clinical considerations, and controversies. Clin Microbiol Rev 1992;5(3):213-37.

10. Patterson JL, Stull-lane A, Girerd PH, et al. Analysis of adherence, biofilm formation, and cytotoxicity suggest a greater virulence potential of Gardnerella vaginalis relative to other bacterial vaginosis associated anaerobes. SGM journal 2010;156(2):392-9.

11. Sobel JD. Vaginitis. N Engl J Med 1997;337(26):1896-903.

12. Schwebke JR. Bacterial vaginosis - more questions than answers. Genitourine med 1997;73(5):333-4.

13. Mangels KI. Collection and transport of clinical specimens for anaerobic culture. In: Issenberg HD, (edi). Clin microbiol procedures handbook. Vol 1. New York: ASM Press 1992:5-6.

14. Nugent RP, Krohn MA, Hillier SL. Reliability of diagnosing bacterial vaginosis is improved by a standardised method of Gram stain interpretation. J Clin Microbiol 1991;29(2):297-301.

15. Adamson PC, Krupp K, Freeman AH, et al. Prevalence and correlates of primary in fertility among young women in Mysore, India. Indian J Med Res 2011;134(4):440-6.

16. Modak T, Arora P, Agnes C, et al. Diagnosis of bacterial vaginosis in cases of abnormal vaginal discharge: comparison of clinical and microbiological criteria. J Infect Dev Ctires 2011;5(5):353-60.

17. Uma $S$, Balakrishnan $P$, Murugavel $K G$, et al. Bacterial vaginosis in women of low socio-economic status in slum areas in Chennai, India. Sex health 2006;3(4):297-8. 
18. Kosambiya JK, Desai VK, Bharadwa JP, et al. RTI/STI prevalence among urban and rural women of Surat: a community-based study. Indian J sex trans dis 2009; 30(2):89-93.

19. Becker M, Stephen J, Moses S, et al. Aetiology and determinants of sexually transmitted infection in Karnataka State, South India. Sextransm dis 2010;37(3): 159-64.

20. Thulkar J, Kripali A, Agarwal M, et al. Aetiology and risk factors of recurrent vaginitis and its association with various contraceptive methods. India J Med Res 2010;131:83-7.

21. Agarwal A, Devi P, Jain R. Anaerobes in bacterial vaginosis. Indian Journal of Medical Microbiology 2003; 21(2):124-6.

22. Lata I, Pradeep Y, Sujata, et al. Estimation of the incidence of bacterial vaginosis and other vaginal infections and its consequences on material/fetal outcome in pregnant women attending an antenatal clinic in a tertiary care hospital in north India. Indian J community med 2010; 35(2):285-9.

23. Patel V, Weiss HA, Mabey $D$, et al. The burden and determinants of reproductive tract infections in India: a population-based study of women in Goa, India. Sex transm Infect 2006;82(3):243-9.

24. Mania-Pramanik J, Kerkar SC, Salvi VS. Bacterial vaginosis: a cause of infertility? Int J STD AIDS 2009; 20(11):778-81.

25. Shethwala ND, Mulla SA, Kosambiya JK, et al. Sexually transmitted infections and reproductive tract infections in female sex workers. Indian J Pathol Microbiol 2009; 52(2):198-9.

26. Ray K, Bala M, Gupta SM, et al. Changing trends in sexually transmitted infections at a regional STD centre in north India. Indian J Med Res 2006;124(5):559-68.

27. Gillet E, Meys JF, Verstralen H, et al. Bacterial vaginosis is associated with uterine cervical human papilloma virus infection: a meta-analysis. BMC infectious diseases 2011;11:10.

28. Rivers CA, Adaramola 00, Shcwebke JR. Prevalence of bacterial vaginosis and candidiasis mixed infection in a south eastern American STD Clinic. Sex Transm Dis 2011;38(7):672-4.

29. Esim BE, Kars B, Karsidag AY, et al. Diagnosis of vulvovaginitis: comparison of clinical and microbiological diagnosis. Arch Gynaecol Obstet 2010;282(5):515-9.

30. Xiao BB, Liu ZH, Liao QP. Microecological investigation of vaginal microflora in women with varying degree gynaecologic symptoms in clinics. Zhonghua $\mathrm{Fu}$ Chan KeZaZhi 2009;44(1):6-8.

31. Ganju SA, Sharma NL. Initial assessment of scaled up sexually transmitted infection intervention in Himachal Pradesh under National AIDS Control Program-III. Indian J Sex Transm Dis 2012;33(1):20-4.

32. Rao PS, Devi S, Shriyan A, et al. Diagnosis of bacterial vaginosis in a rural setup: comparison of clinical algorithm, smear scoring, and culture by semiquantitative technique. Indian journal of Medical Microbiology 2004;22(1):47-50.
33. Bhalla $\mathrm{P}$, Chawla R, Garg $\mathrm{S}$, et al. Prevalence of bacterial vaginosis among women in Delhi, India. Indian J Med Res 2007;125(2):167-72.

34. Bogaerts J, Ahmed J, Akhter N, et al. Sexually transmitted infections among married women in Dhaka, Bangladesh: unexpected high prevalence of herpes simplex type 2 infection. Sex Transm Inf 2001;77(2):114-9.

35. Yongjun T, Samuelson J, Qingsheng D, et al. The prevalence of sexually transmitted and other lower reproductive tract infections among rural women in Sichuan Province, China. Southeast Asian J Trop Med Public Health 2009;40(5):1038-47.

36. Liu YJ, Wang XF, Song L, et al. The sexual behaviour characteristics and STD infection status of women who have sex with women in Beijing. Zhonghua Yu Fang Yi Xue Za Zhi 2012;46(7):627-30.

37. Sumati AH, Sarith NK. Bacterial vaginosis with special reference to anaerobes. Indian Journal of Pathology and Microbiology 2009;52(1):56-8.

38. De Figueiredo LSR, de Amorim MM, Calabria WB, et al. Clinical and microbiological profile of women with bacterial vaginosis. Rev Bras Gynaecol Obstet 2010;32(2):82-7.

39. Hapsari ED, Hayashi M, Matsuo H. Clinical characteristics of vaginal discharge in bacterial vaginosis diagnosed by Nugent's criteria. Clin Exp Obstet Gynaecol 2006;33(1):59.

40. Hainer BL, Gibson MV. Vaginitis: diagnosis and treatment. Am Fam Physician 2011;83(7):807-15.

41. Schwebke JR, Hillier SL, Sobel JD, et al. Validity of the vaginal Gram stain for the diagnosis of bacterial vaginosis. Obstet Gynaecol 1996;88(4 Pt 1):573-6.

42. Gallo MF, Jaieson DJ, Cu-Uvin S, et al. Accuracy of clinical diagnosis of bacterial vaginosis by human immunodeficiency virus infection status. Sex Transm Dis 2011;38(4):270-4.

43. Tam MT, Yunbluth M, Myles T. Gram stain method shows better sensitivity than clinical criteria for detection of bacterial vaginosis in surveillance of pregnant lowincome women in a clinical setting. Infect Dis Obstet Gynaecol 1998;6(5):204-8.

44. Gratacos E, Figueras F, Barranco M, et al. Prevalence of bacterial vaginosis and correlation of clinical findings to Gram stain diagnostic criteria in low risk pregnant women. Eur J Epidemio 1999;15:913-6.

45. Sachdeva S. Clue cell. Indian J Dermatol Venereol Leprol 2006;72(5):392-3.

46. Khan SA, Amir F, Altaf S, et al. Evaluation of common organisms causing vaginal discharge. J Ayub Med Coll Abbottabad 2009;21(2):90-3.

47. Wang XF, Norris JL, Liu YJ, et al. Health-related attitudes and risk factors for sexually transmitted infections of Chinese women who have sex with women. Chin Med J 2012;125(16):2819-25. 